\title{
Vanguardia. Ideología, Mito (En Torno a una Novelística Reciente en Cuba)
}

¿Cómo escribir desde la revolución? El debate cubano sobre este tema empieza en 1959 en los tanteos eclécticos del semanario Lunes de Revolución y se extiende mucho en los años 60 al producirse el boom editorial y creador fuera de Cuba y dentro de ella, donde los organismos culturales alientan una muy respetable producción literaria. La discusión teórica e ideológica que acompaña esta eclosión de nueva literatura intenta plantear bases para la valoración del quehacer literario en las condiciones de subdesarrollo, reorganización institucional y defensa nacional. Es notable en esta discusión-en los textos presentados al Congreso Cultural de La Habana de enero de 1968, por ejemplo-la supervivencia del concepto de vanguardia. Históricamente, el pensamiento de izquierda ha intentado aproximar la vanguardia artística a la vanguardia política revolucionaria, acercamiento efectuado sólo esporádicamente en este siglo de vanguardismos pero que sigue ejerciendo su atracción. Así la colaboración de Adolfo Sánchez Vázquez al Congreso Cultural observa que el divorcio de las dos vanguardias (en condiciones prerrevolucionarias o en sociedades posrevolucionarias como la URSS) ha colocado a la vanguardia artística en el "escapismo" y a la vanguardia política en una actitud que subordina el arte a "objetivos políticos inmediatos'. ' Tanto Sánchez Vázquez como Jesús Díaz y Juan Valdés-Paz postulan experimentación y búsqueda en el plano estético e integración de esa búsqueda al proyecto revolucionario de la sociedad, función esta última potencial pero no garantizada en todo movimiento vanguardista. "Desde este punto de vista (dicen Díaz y Valdés)

el tratamiento de vanguardia a un autor u obras, solamente por sus valores artísticos, aún en términos contemporáneos será puramente adjetivo y referido a su ubicación en la historia de esa rama. Su marginalidad de toda obligación ética inmediata con la nación y su cultura (su defensa, su enriquecimiento, su promoción, etc.) no le conferirán el carácter sustantivo de vanguardia, entendido instrumentalmente. Por otra parte, no olvidemos que tampoco será aplicable a aquellos movimientos que llenos de las sabidas buenas intenciones, abandonen la

1 "Vanguardia artística y vanguardia politica", en M. Benedetti, et al., Literatura y arte nuevo en Cuba, Barcelona: Estela, 1971, pág. 95. 
búsqueda y no acepten los riesgos de la experimentación en aras de un sociologismo no por bien intencionado menos negativo. ${ }^{2}$

Estos programas se valen de la experiencia del arte en este siglo y se definen en contra del zdanovismo y de la aislación minoritarista, peligros ambos en la situación concreta de Cuba, donde los artistas se ven estimulados no sólo por la experiencia de una revolución audaz y en sí imaginativa, sino también por las influencias culturales de uno y otro de los mundos económicamente desarrollados. En un texto inteligente y equilibrado de 1969, el escritor René Depestre, haitiano de larga residencia en la Cuba revolucionaria, previene, él también, contra las soluciones demasiado fáciles para la práctica de la literatura en la revolución: contra el reduccionismo simplista que supeditaría la literatura a una función militante y didáctica, y contra la mecánica trasposición al medio revolucionario de la postura opositora del vanguardismo en la sociedad burguesa. ${ }^{3}$ Depestre insiste en la especificidad de la literatura y en la distinción entre literatura y pedagogía general. Absolvería al escritor de la consigna de componer "una epopeya a cada hazaña, . . . una obra maestra después de cada acontecimiento que estremezca emocionalmente a la comunidad" ". Hace notar que Rusia esperó cincuenta años a un Tolstoi que lograra la épica de la invasión napoleónica. Echando mano a una modalidad que ha influído en su propia poesía, Depestre hasta propone una actividad literaria análoga en su ejercicio imaginativo y en su empeño por cambiar la vida en todos los órdenes a "lo que fue en su mejor época el surrealismo europeo" y da por sentado que el escritor revolucionario de ahora no caería en el error surrealista de "esperar la liberación del hombre sólo de la emancipación de las facultades poéticas de su espíritu' '5 Ya que Depestre habla desde una actitud de compromiso total con la revolución y ve en la escritura una manera de descolonizar, es claro que lo que él ataca aquí es la interpretación demasiado literal de la relación entre la literatura y la historia en marcha.

Con planteos teóricos como los citados, se clausura una etapa de la búsqueda de una definición de vanguardia idónea a la revolución. En el terreno más concreto de la producción literaria, los años 60 habían visto, en la narrativa, por ejemplo, la publicación de obras jóvenes tan diversas en su relación a la historia inmediata y en su elaboración técnica como Los años duros de Jesús Díaz (1966) y Celestino antes del alba de Reinaldo Arenas (1967), como Condenados de Condado de Norberto Fuentes y Siempre la muerte, su paso breve de Reynaldo González (ambos de 1968). Esta gama amplia de experimentación encontró su defensa en la especulación a nivel de teoría.

II

Una nueva etapa comienza a destacarse en 1970, a pocos meses de la propuesta de René Depestre. Y resulta que la historia sobrepasa momentáneamente al esquema intelectual. Una hazaña nacional-la zafra de los diez millones-moviliza a toda la

2 "Vanguardia, tradición y subdesarrollo", en Literatura y arte nuevo, pág. 71-72.

3 Depestre, "El poder de la literatura en la sociedad socialista", intervención en una mesa redonda en La Habana, 2 de mayo de 1969, reproducida en A. Sánchez Vázquez, ed., Estética y marxismo, tomo II, pág. 357.

4 Depestre, pág. 358.

5 Depestre, pág. 356. 
comunidad y en lo literario estimula justamente una producción "epopéyica"' (narrativa, testimonial, poética) alusiva a los hechos del momento. ${ }^{6}$ A raíz de esta producción, la revista Casa de las A méricas señala un cambio en la novelística, la forma que hasta entonces se había mostrado acaso más resistente a una referencia literal a la historia en marhca. ${ }^{7}$ En 1970 gana el Premio Casa de novela Sacchario de Miguel Cossío Woodward, un intento de narrar la participación voluntaria en la zafra. Comentando Sacchario, Ambrosio Fornet, miembro del jurado que la premió, critica en la novelística anterior una timidez ante la posibilidad de exaltar literalmente la revolución y saluda en el texto de Cossío Woodward un heraldo posible de otra fase: la entrada de la novela en la "épica de vanguardia". ${ }^{8}$ Invirtiendo un tanto la definición de vanguardia de un Depestre, Fornet ve como positiva la presentación de un protagonista en su desarrollo como revolucionario, aunque esa historia está narrada " a veces como una evocación y otras como una arenga, en el tono del discursoo del diario". 9 . Lo que le parece distintivo a Fornet es el origen del personaje, Darío, como niño huérfano en la prerrevolución inmerso en el mundo importado de Mandrake y el Pato Donald, su paso a militante revolucionario y finalmente su renuncia a conformarse con la revolución conseguida, en el momento en que se mete a voluntario en el corte de caña. Más humilde en su origen y más ejemplar en su actuación que el acomodaticio anti-héroe de Memorias de subdesarrollo de Edmundo Desnoes, este Dario, para Fornet, " no trata de purificarse para ser otro y ajustarse a las nuevas exigencias, sino para no dejar de ser él mismo y permanecer fiel a su imagen del revolucionario", 10

El criterio temático de Fornet podría convencernos si Saccbario presentara un personaje bien dibujado. El desarrollo de semejante vida no es inverosímil en Cuba, y sin duda valdría la pena dejar constancia de ello en una novela. Pero el texto premiado falla precisamente en los largos fragmentos retrospectivos que reconstruyen la biografía de Darío. En el más logrado tiempo presente de la novela-segmentada en mañana, tarde y noche de un solo día en el campamento de macheteros-Dario y sus compañeros adquieren vida. Cossío Woodward se interna en la experiencia inmediata de los trabajadores, comunicando impresiones rápidas y gráficas a través de la corriente de la conciencia. Resultan plausibles las sicologías y se expresa eficazmente la ardua dificultad de la labor. Cuando la narración se concentra en el recuento del desarrollo revolucionario de Darío, se vuelve esquemática y discursiva. El personaje desaparece bajo una avalancha de palabras que lo interpretan de manera casi abstracta:

Pero Darío empezaba a comprender que aquellos acontecimientos dispersos, aislados, que ocurrían sin aparente conexión, formando una cadena de situaciones y creencias a las que normalmente se acostumbraba todo el mundo, porque eran

6 Véase la selección de textos motivados por la zafra en Casa de las Américas, Año XI, 62 (sept.-oct., 1970), pág. 110-118. Se incluye un texto testimonial de René Depestre, uno de los mejores del conjunto.

7 La cuentística de la década del 60 contaba con excelentes textos francamente inspirados en la historia militar revolucionaria (Los años duros, Condenados de Condado) y en otros hechos revolucionarios (El escudo de bojas secas, de Antonio Benitez Rojo, 1968). Las novelas de mejor elaboración pareclan evitar la alusión literal a la historia revolucionaria.

8 Fornet, "A propósito de Sacchario", Casa de las Américas, Afoo XII, 64 (enero-feb., 1971), pág. $183-186$.

9 Fornet, pág. 184.

${ }^{10}$ Fornet, pág. 186. 
propias de la vida diaria, cosas simples, inevitables, eran hechos que ocurrían realmente en un marco más general, más amplio; en la sociedad, en la historia.

Hay, además, un serio error hacia el final de esta prehistoria de Darío (es el final también de la novela), cuando en vez de explorar, sólo se alude a la relación del protagonista con su mujer y su ruptura con ella, con "la mediocre ficción de hogar, familia, qué dirán" . ${ }^{12}$

Será la promesa de Sacchario, más que sus logros, lo que motiva la discusión de Fornet, quien menciona de pasada que "muchas objeciones podrán hacérsele a Sacchario pero no la de no ser una novela de nuestro tiempo". 13 Y lo que Saccbario promete, acaso, es esa "épica de vanguardia" no temerosa de exaltar la experiencia militante ni de "caer en el panfleto', recelo que Fornet critica en la novelística anterior. ${ }^{14}$ El concepto de vanguardia esbozado por Depestre en 1969 tiende a diferenciar más claramente literatura y difusión ideológica (sin excluir de las obras literarias ni el tema ni el tono de la revolución); Fornet aquí celebra una verdadera caída en el panfleto. Aunque Sacchario no quepa dentro del estrecho marco del realismo zdanovista, sí ostenta una contradicción irresuelta entre una voluntad de caraterizar plenamente al protagonista y de comunicar la ideología del hombre nuevo. Ambas funciones tendrían cabida en una novela, pero sólo si se dramatizara consistentemente la ideología y si se ahondara consistentemente en la caracterización.

\section{III}

En 1971 y 1972, en tiempos de recuperación económica y de cierta desmoralización en algunos sectores cubanos, Casa de las Americas sigue observando y alentando la actitud "'épica"' en otras novelas. Antonio Benítez Rojo considera a Para matar el lobo de Julio Travieso (1971) - novela de acción que representa desde dentro la guerrilla urbana contra Batista-como "una feliz incursión en la épica de vanguardia" $]^{5}$ Y José Antonio Portuondo califica de "épica de la edificación socialista" a la última mujer y el próximo combate, de Manuel Cofiño López, Premio Casa 1971.16 Por la elaboración superior de esta novela, servirá aquí de indicio de las posibilidades imaginativas dentro de una temática orientada hacia el mundo del hombre trabajador o de la construcción comunitaria. ${ }^{17}$

La última mujer y el próximo combate acusa alguna semejanza formal con la novela de Cossío Woodward premiada el año anterior. Ambas obras se nutren de la primera nueva novela hispanoamericana: espacialización formal, diversificación de voces narrativas, incorporación de los lenguajes demótico y poético. La novela de Cofiño López varía su relato lineal con narraciones retrospectivas y otros materiales que introducen las voces de la colectividad. Este contrapunto es más complejo y más funcional que el de Sacchario,

${ }^{11}$ Cossio Woodward, Sacchario, La Habana: Casa de la Américas, 1970, pág. 125-126.

12 Sacchario, pág. 245.

13 Fornet, pág. 186.

${ }^{14}$ Fornet, pág. 183.

${ }^{15}$ Benítez Rojo, "Para matar al lobo", Casa de las Americas, Año XII (marzo-abril, 1972), pág. 107-108. 106

${ }^{16}$ Portuondo, "Una novela revolucionaria", Casa de las Américas, Año XII (marzo-abril, 1972), pág. 105-

17 Cofiño López, La última mujer y el próximo combate, La Habana: Casa de las Américas, 1971. Aquí se citará por la segunda ed., México: Siglo XXI, 1972. 
desplazando la perspectiva con agilidad. El relato lineal en si establece, como en Sacchario, un espacio representacional, un lugar de trabajo plausible, especifico, pero que condensa en sí la dialéctica del proceso cubano en general: progreso hacia el desarrollo y resistencia del medio natural; reforma institucional y recalcitrancia subjetiva; supervivencia de desniveles entre ciudad y campo, intelectual y obrero. Así funcionan simbólicamente como crisoles de la acción revolucionaria el Plan de desarrollo forestal, donde transcurre la acción presente de La ultima mujer, y el campamento azucarero de Sacchario. En Sacchario se pormenorizan los hechos de un día típico de corte de caña voluntario; los problemas esbozados vienen a ser cuestiones de incentivo en el trabajo o dificultades con el ambiente (un incendio en el cañaveral). La última mujer aborda un problema administrativo más que los problemas personales de los trabajadores-la necesidad de reorganizar el Plan Forestal para acabar con la corrupción y la ineficiencia que lo aquejan.

El personaje de Bruno, que al principio de la novela llega al Plan como el nuevo director, se asemeja en su función significativa ejemplar al Dario de Sacchario: también en el caso de Bruno una narración retrospectiva expone su progreso como revolucionario, progreso que ha implicado la ruptura con la mujer, la militancia, la reformación de la conciencia. Estos flasbbacks son menos extensos y menos discursivos que los fragmentos correspondientes de Sacchario y no llegan a dominar la novela.

En Sacchario, el código ideológico abruma en su prolijidad, deshace la ilusión novelistica. Cofiño López tiende a integrar mejor el código ideológico a la textura dramática de los hechos. Lo establece inicialmente con el epígrafe liminar, que viene a ser un parlamento de Bruno acerca de la necesidad de preocuparse por el individuo en la revolución, de ver tanto los pinos como el pinar. Esta formulación, reminiscente de " $\mathrm{El}$ socialismo y el hombre en Cuba', del Che Guevara, coloca a Bruno en el centro moral del libro, lo privilegia de antemano. Con lo cual, y aun considerando toques mecánicos de caracterización (la vena saliente que late en la frente de Bruno en sus frecuentes momentos de indignación burocrática), este personaje no resulta tan inefable como el protagonista de Sacchario. La última mujer intenta cumplir literariamente la consigna del epigrafe: crear personajes dentro de un cuadro de acciones revolucionarias (y contrarrevolucionarias). Con este motivo, Cofiño López alivia la historia del destino del Plan Forestal con una subtrama que ahonda en la vida de dos matrimonios, trabajadores los hombres en el Plan, las mujeres dependientes de ellos. El relato del adulterio de Siaco y Nati, que traicionan a Claudia y a Clemente, respectivamente, tiene su propio peso como historia de pasión y es vinculado a la trama principal en la figura de Siaco, tipo criminal cuyo egoísmo y obstruccionismo conducen al desenlace: la emboscada que él pone a Bruno y que resulta fatal para ambos. (Es claro que Cofiño López no está tampoco exento de las caracterizaciones esquemáticas).

\section{IV}

Un elemento contrapuntístico que añade perspectivismo y ambientación a La última mujer son los fragmentos puestos en boca de una vox populi que a lo largo de la novela cuenta leyendas, mitos, rumores, relatos que pintan la antigua situación prerrevolucionaria en la zona del Plan. Estas secciones constituyen el lugar de la superstición y de la inexactitud, del "dicen que decían" contrastado con las ideas y objetivos 
claros asociados con el Plan y con Bruno. El contraste acentúa las diferencias sociales y regionales que quedan por resolver en Cuba y en otras partes de Latinoamérica:

Dicen que son llamitas. Dicen que cuando hay luna y no hay estrellas y el cielo se pone color ceniza, no es raro ver llamas errantes. Se detienen en los pinos, en las ruinas de algunas casas, en los brocales de los pozos sin agua, en el fondo de las cañadas secas; dicen que son almas de difuntos, atados a la tierra por lazos malditos. Dicen que se arremolinan como los pelos de las mujeres cuando les da el viento; como si un viento implacable las agitara y que se extinguen en el aire cuando se les reza una oración o se saca el cuchillo y se le pone en cruz sobre la vaina. ${ }^{18}$

Lo sabroso, lo localista de estos murmullos en vox populi (muchas veces identificable ésta como la voz de un viejo narrador, Anastasio Ríos) es balanceado no sólo por la yuxtaposición de la mentalidad tradicional a la progresista sino por comentarios más obvios como éste adjudicado a una obrera, Mercedes, que ha captado la atención de Bruno y que se ha enamorado de él:

Esas son supersticiones que yo sé que a él no le gustan porque la noche de la inundación la gente habló de eso, hizo cuentos de eso, y él nos dijo a Claudia y a mí que eso era producto de la ignorancia y la sugestión y que si hubiera luz en todo el monte como en las ciudades, la gente no vería tantas cosas raras. ${ }^{19}$

El enfrentamiento de dos cosmovisiones (con su presunta resolución a nivel del código ideológico) significa, para Portuondo, una contestación a la línea narrativa hispanoamericana que intenta integrar a su óptica la visión de la América primitiva:

(En las páginas de La úliima mujer) resalta la viva contradicción entre una concepción del mundo precientífica, mágica, responsable, en parte considerable de ese "real maravilloso" cuyo cultivo inicia Alejo Carpentier y que culmina con Cien años de soledad, de Gabriel García Márquez, y los novísimos parámetros impuestos por la interpretación marxista-leninista de la misma realidad enfrentada por aquella. E1 Plan de desarrollo forestal y agrario en el que transcurre la novela es el polo opuesto de Macondo. . Lo mágico, lo "real maravilloso" es aquí la visión caduca y pintoresca, mítica, que va quedando atrás, sobrepasada sin violencia por la nueva conciencia socialista, cientifica, revolucionaria. ${ }^{20}$

Esa visión mítica va quedando atrás. Portuondo acierta al representar este movimiento como una transición, y no como una superación. Porque la relegación del mito no es aquí total. Acaso no lo sea nunca en la ficción. En todo caso, esta novela participa de varias maneras en visiones míticas. El evidente placer con el que Cofiño López elabora los fragmentos legendarios es muestra de la tenacidad del costumbrismo ruralista aun hoy ofrecido como modelo para el escritor que quiere representar el medio rural. Otra tregua del autor con la visión de la vox populiestá en el uso de esa imaginación para la significación ideológica progresista. Entre las figuras prerrevolucionarias que protagonizan algunas de las breves narraciones ingenuas, se destaca la del terrateniente grosero, sobrealimentado,

18 La ultima mujer, pág. 106.

${ }^{19}$ La última mujer, pág. 252-253.

${ }^{20}$ Portuondo, pág. 106. 
Alejandro La O. Pero también emerge otra figura positiva, la de un hombre que se fue a la guerrilla rural contra el Batistato, è barbudo Pedro el Buldocero o Pedro Buldoza, que dejó un letrero en su máquina: "me alcé". Pedro el Buldocero, tal como lo retrata la vox populi, forma paralelo con la figura de Bruno, hasta en su desprecio de las supersticiones, pero el buldocero en si vale como una figura legendaria. La revolución crea leyendas y héroes, se arraiga en la imaginación colectiva y se hace mítica. La revolución como mito rebasa, además, el marco de la vox populiy contagia a la otra narración, la que no se supone ingenua, como cuando se hace recordar a Bruno antes del combate final la famosa alusión del Che Guevara a un cuento de Jack London recordado por Guevara antes del combate de Alegría del Pío. Esıe (1esonante) intento de acentuar la importancia del sacrificio del personaje es comparable, mutatis mutandis, a la superimposición de imágenes de Cristo sobre el héroe de tantas ficciones producidas en las culturas cristianas. En cuanto "épica", La uiltima mujer toca aspectos históricos y míticos del proceso de adaptación al socialismo. $\mathrm{Al}$ rechazar (de modo parcial) la superstición rural, la novela no deja de activar leyendas progresistas que se consideran más válidas y actuales.

Un ejemplo más para ilustrar que la óptica de esta novela no está desligada de lo irracional: se trata de algunas asociaciones simbólicas caracterizadoras que ligan ciertos personajes a elementos del paisaje. Asi la mujer Nati tiene la compulsión de correr desnuda bajo la lluvia, o de ótro modo sumergirse en el agua. De larga, demasiado larga ascendencia en la narrativa hispanoamericana (un antecedente reciente: Remedios, la Bella, de Cien años de soledad), este ser natural y voluptuoso es un misterio y un imán sexual para la gente del Plan. El lector la ve sicológicamente traumatizada (parece estar lavándose de la verguienza de su violación a los 12 años por Alejandro $\mathrm{La} \mathrm{O}$ ) pero también baio el aspecto arquetípico de una asociación general con el elemento liquido. ${ }^{21}$

Es un defecto, acaso un defecto de primera novela, que La última mujer se sirva de clisés literarios como la figura de Nati, que no aparece en el marco de ninguna distanciación irónica. Lo que no se excusa es que esta caracterización forma parte de toda una actitud hacia los papeles sexuales que llega a la novela sin pasar por el tamiz crítico que seria propio a un marxismo activo. Nati corresponde a un arquetipo literario de la mujer concebida, claro está, por novelistas masculinos. Es significativo que la primera unión de Siaco con ella ocurre tras una escena de voyuerismo pastoril: él la sorprende bailando desnuda, como alocada o como en un rito, bajo una tormenta de lluvia, y la viola. No sorprende en este contexto que la furia sexual del varón se represente como una fuerza avasalladora, aun cuando la violación quepa en el esquema de inmoralidades de Siaco:

-Siaco...y si viene Clemente.... Siaco.... Vete.

Pero Siaco no quiso oír más, y tirándola sobre la tierra cayó sobre ella y le tapó la boca con su boca hasta que cesaron los sollozos. Entonces, poco a poco, entre la

${ }^{21}$ Cofiño López sigue explorando las posibilidades del abundante material mítico en Cuba en una novela que ahora prepara. Una mitad del fragmento que publicó recientemente es una descripción del dios Osain, "el amo de los palos y bejucos, de las flores y matas, de los árboles y hojas, de sus amores y poderes"'. Este texto genera su propio interés pero va yuxtapuesto a otro ya no mítico sino de ambiente novelesco ("Cuando la sangre se parece al fuego", en La Gaceta de Cuba, 121 [marzo, 1974] ], pág. 8-9). 
lluvia que le caía sobre la espalda, sintió las manos de Nati. Los labios de Nati entreabiertos, su cuerpo retorciéndose jadeante, mojado y resbaloso, y sus ojos muy abiertos y asustados, como brechas abiertas en oscura canada. Cerró los ojos y quedó como dormida. E1 agua le corría por la cara. Después, meses después, le diria: "Tú me entraste por la piel. Tenías la piel tibia y yo estaba fría. Siaco, lo que más me gusta de ti es la piel, esa piel, ese color moreno de tabaco mal secado que tienes. Siaco, eres como un remedio'?. ${ }^{22}$

Si esta sumisión de Nati uera contrastada con otra figura de mujer que se comportase en calidad de igual ante los hombres, se comprendería como factor de la situación particular de la Nati-víctima del sistema pre- y contrarrevolucionario. Pero también cae dentro del estereotipo Mercedes, trabajadora extraordinaria, "'vanguardia del Plan", que gira alrededor de la figura de Bruno, sirve en gran parte como factor caracterizador de él, con su actitud de mujer a la expectativa, pendiente de la iniciativa del varón. En el universo de $L a$ última mujer, son los hombres los que mueven la acción: Bruno y su equipo masculino, que emprenden la reorganizaciön del Plan Forestal; malhechores como Siaco y Alejandro $\mathrm{La} \mathrm{O}$; un héroe como Pedro el Buldocero. De un dicho de éste procede el título de la novela, que anuncia una situación narrativa protagonizada por el hombre y en la que la mujer queda objetivizada sólo como otra experiencia en la sucesión de amores y luchas que prueban el valor del varón. En este punto ideológico Cofiño López se coloca a la retaguardia del proceso cubano, cuyos sectores progresistas están enfrentando las contradicciones de la estructuración patriarcal de una sociedad en vías de transición al socialism ${ }^{23}$ Resulta acaso más extraño este aspecto de La última mujer en vista de que se publicóa dos años del estreno de Lucia, el film de Humberto Solás que aborda de manera crítica la cuestión del papel sexual de hombres y mujeres en la sociedad cubana, antes y después de la revolución.

$\mathrm{VI}$

Sacchario y La última mujer y el proximo combate son las primeras novelas de sus autores. ${ }^{24}$ Acaso sea prematuro hacer un juicio de su calidad literaria hasta que se conozcan más textos de uno y otro escritor. Sí parece lícito y preciso comentar brevemente al concluir el presente trabajo la línea crítica ejemplificada en los textos ya mencionados de Ambrosio Fornet, de José Antonio Portuondo y de Antonio Benitez Rojo. Dejando de lado la comprensible influencia que ejerciera en estos comentaristas el momento histórico de esos años de 1971 y 1972, se puede observar que el criterio definitorio de las designaciones "épica de vanguardia", "épica de la edificación socialista", es temático. La vanguardia aludida es la ideológica, ya que estos textos no innovan en el medio expresivo ni los comentaristas exploran a fondo la elaboración textual. El entusiasmo de Fornet por el personaje de Sacchario es un ejemplo de la crítica que se encamina apresuradamente a los

${ }^{22}$ La ultima mujer, pág. 158-59.

${ }^{23}$ Una organización de base que se ocupa de reivindicar a la mujer es la Federación de Mujeres Cubanas. Un decreto importante para la liberación de la mujer en Cuba es la ley de maternidad de enero de 1974. Fidel Castro reconoció la importancia del nuevo papel de la mujer cubana en el discurso de clausura de una reunión nacional de la FMC, identificando ese nuevo papel como una revolución en la revolución.

${ }^{24}$ Cossio Woodward era autor inédito antes de ganar el Premio Casa. Cofiño López había publicado anteriormente Tiempo de cambio, una colección de cuentos. 
significados de un texto sin fijarse en los significantes. El peligro aqui para una critica que quiere ser marxista (y para una critica influyente como la que aparece en Casa de las Américas) es contentarse con lo que Díaz y Valdés designaran como "las sabidas buenas intenciones" ', sin requerir que éstas se transformen en concreciones literarias. Así como el pensamiento marxista de verdad busca concretar, vencer la abstracción, la trasposición de la ideología a la escritura imaginativa requiere concreción mediante un uso sensible y crítico del medio lingúístico y de la estructuración formal. La actitud crítica del autor ha de aplicarse también, desde luego, a la misma ideologia que él maneja. El comentario de Portuondo a la ideología de La última mujer serviria más a la edificación socialista si el crítico puntualizara los aspectos anti-liberadores de la obra junto con los aspectos progresistas.

Fornet, Portuondo y Benítez Rojo avanzan severos juicios de la producción novelística de los años 60, otra vez desde el punto de vista temático-ideológico: la escasez de héroes positivos y proletarios o campesinos, el miedo a la exaltación revolucionaria, predominio de una óptica irracional-mágica. La objeción puede ser acertada. Muchas novelas de los años 60 no están coordenadas de manera directa con la ideología del socialismo. Pero como se ha demostrado aquí, tampoco lo está del todo La última mujer, y esto sugiere que el proceso de adecuación de la ideología a la escritura es compleia y diffcil. Los escritores del 60 son, muchos de ellos, de formación prerrevolucionaria y esto purede influir en su eclecticismo ideológico. Lo que sí vale en novelas como Los niños se despiden de Pablo Armando Fernández (1968) o en Siempre la muerte, su paso breve de Reynaldo González (también de 1968) es el cuidado de su elaboración, que posibilita, en lo temático, la representación profunda de la experiencia humana-meta también de una literatura imaginativa marxista. Los escritores jóvenes cometerán una injusticia consigo mismos si desatienden de los logros positivos de la novelística del primer decenio de la revolucióni. ${ }^{25}$

Bryn Mawr College

JOHN F. DEREDITA

25 El autor quiere agradecer al Madge Miller Research Fund de Bryn Mawr College un estipendio que facilitó su investigación. Tambiên al Center for Cuban Studies de Nueva York por facilitarle textos diffciles de encontrar en otra parte. 
